\title{
EL DOLO Y LA CULPA EN LA ESTRUCTURA DEL SISTEMA \\ PENAL MEXICANO
}

\section{Eduardo Lozano Tovar ${ }^{1}$}

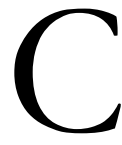

on regularidad, los operadores del sistema penal mexicano, responsables de las trascendentales y graves tareas de procurar y administrar justicia, en el momento de la materialización de sus decisiones — ya desde el papel de agente del Ministerio Público o desde el papel de juzgador-, se encuentran más preocupados de la substanciación del hecho típico, de satisfacer los requisitos de la norma, y en esa inercia de analizar el dolo y la culpa, el ejercicio mecanicista se impone sin ninguna restricción.

Sea por la carga de trabajo, sea por la formación doctrinal o sea por desconocimiento de la integralidad de la norma, el operador jurídico no otorga un peso sustantivo en su quehacer a la perspectiva que en estos dos conceptos - dolo y culpa - tienen las teorías del causalismo y finalismo, que se integran de modo imbíbito en el ordenamiento penal, y por consecuencia, guardan una notable influencia en el comportamiento de ministerios públicos y jueces, aunque ellos muy probablemente no lo sepan.

En esta oportunidad, habremos de acercarnos a revisar de modo sucinto, algunas consideraciones de orden dogmático jurídico penal respecto del delito, y la relación que algunos de los más importantes tipos penales — por su impacto en la percepción social— guardan con las doctrinas de mayor trascendencia en el ámbito penal de los últimos cien años, y cómo la óptica doctrinal influye en la construcción de la norma penal

1 Doctor en Derecho por la Universidad Autónoma de Tlaxcala, académico en la Facultad de Derecho, Ciencias Políticas y Criminología, miembro del Sistema Nacional de Investigadores del Consejo Nacional de Ciencia y Tecnología, Nivel 1, e integrante de la International Legal Fraternity Phi Delta Phi, con sede en Washington, D.C., EUA. Cultiva la línea de investigación de política criminal y criminológica. 
para interpretar, desde la mirada del legislador, el dolo y la culpa como elementos positivos del delito.

\section{Devenir de las doctrinas alemanas del causalismo y finalismo}

En la comprensión de los elementos que integran al derecho penal, el delito es el ente central que explica — además de la sanción, por supuesto- la estructural doctrinal generada a partir de la historia en que ha devenido el derecho punitivo en la humanidad.

Todo conocimiento social se constituye a partir de una lógica material para que su pertinencia satisfaga las necesidades de ese momento, de ese espacio, y de esa sociedad en un momento determinado. No es casual, entonces, que en el ocaso decimonónico y en los albores del siglo XX, los estudios en materia jurídico penal se vinculen a rescatar los pendientes conceptuales que las diferentes escuelas y corrientes del pensamiento penal en el mundo occidental.

Y la escuela dogmático formalista alemana es la que desde el siglo XIX, plantea ya las condiciones de estudio del derecho penal. Autores como Karl Stubel y Heinrich Luden, habían hecho suyo el estudio del delito en su concepción objetiva hacia la primera mitad de ese siglo, estudios base para la consideración penal objetiva. Pero es con otros juristas como Franz von Liszt y Ernst von Beling quienes dan el basamento en el marco de la teoría del delito a la corriente causalista.

Franz von Liszt se ubica como el incipiente pero a su vez sólido expositor del causalismo, al advertir que la "acción” es el aspecto causal en el hecho delictivo. En el Código Penal alemán de 1871, Liszt realiza un análisis dogmático en el cual a partir de las escuelas clásica y positivista, concibe su discurso alrededor de la acción como base fundamental en el nexo causa-efecto del delito.

Para el creador del Marburger Program, "el delito (acto punible) es el hecho al cual el orden jurídico asocia la pena como legítima consecuencia", 2 es decir, deriva de un orden creado ex profeso por la figura del Estado. De esa idea se aprecian tres condiciones esenciales:

2 LISZT, Franz von, Tratado de derecho penal, vol. II (trad. Luis Jiménez de Asúa), Ed. Reus, Madrid, 2007, p. 262. 
a) El delito es siempre un acto humano; por tanto, actuación (Verbalten) voluntaria trascendente al mundo exterior; es decir, la causa o no impedimento de un cambio en el mundo exterior. Nunca llegarán a constituir un delito los acontecimientos fortuitos, independientemente de la voluntad humana.

b) El delito es, además, un acto contrario al derecho, es decir, un acto que, contraviniendo, formalmente, a un mandato o prohibición del orden jurídico, implica, materialmente, la lesión o peligro de un bien jurídico.

c) El delito es, por último, un acto culpable; es decir, un acto doloso o culposo de un individuo responsable. ${ }^{3}$

Entonces, el hecho típico se presenta, para Franz von Liszt, como un acto observado jurídicamente con dos características: en el elemento esencial de contrario al Derecho (Asúa dixit), recae sobre el autor. De este modo, el concepto del acto, apreciado por el Derecho, se establece como concepto fundamental de la teoría del delito. Cuando falte uno de los tres caracteres esenciales de la idea, entonces no hay delito.

Esta idea que exponemos en esta parte, es la que después el legislador mexicano habría de considerar cuando se crearon las normas que consideraban de modo fehaciente los contenidos que coincidían en la figura del cuerpo del delito, idea que más adelante habremos de retomar para explicarnos los devaneos del legislador mexicano en dotar de un sistema penal basado en el cuerpo del delito a las instituciones procuradoras y administradoras de justicia, con las problemáticas que sobrevinieron en esa expresión de política punitiva o criminal.

Para Liszt, adelantado a su tiempo como lo denota la vigencia de sus constructos teóricos, el legislador no asocia la pena como consecuencia jurídica a toda infracción (Unrecht). Más bien, entresaca del círculo de los actos culpables (Detikte), que apenas puede abarcarse con una sola mirada, ciertos actos exactamente circunscritos, formando así los hechos (particulares), constitutivos de los diversos delitos sancionados con una pena.

${ }^{3}$ Ibídem. 
A la par de la postura causalista de Franz von Liszt, Ernst von Beling en su Teoría del Delito, ampliaba el concepto causal de la acción: "concebía a la acción — en el sentido de una mera causalidad natural_-, como movimiento corporal externo capaz de percibirse por los sentidos provocada por la voluntad humana, sin tener en cuenta la finalidad (o contenido) de la voluntad; el dolo (Vorsatz) pertenecía exclusivamente a la categoría de la culpabilidad (Schuld)". ${ }^{4}$

Beling fundamenta su construcción alrededor del delito en el plano causalista a partir de afirmar que "para comprobar que una acción ha ocurrido basta con la certeza de que el autor actuó voluntariamente o de que permaneció inactivo. Lo que el autor quiso concretamente es indiferente; el contenido de la voluntad (Willensinhalt) sólo es relevante en sede de culpabilidad".

Esto reafirma la identificación con el pensamiento de Franz von Liszt en el aspecto de la voluntad como vertebra de la acción en el delito, doctrina que ha subsistido en el ordenamiento jurídico alemán, y que incluso, de acuerdo a Karl Ambos, reverdece en preámbulo del nuevo siglo:

Por más convincente que resulte la superación de la teoría causal del delito por la teoría post finalista del mismo en el seno de la discusión alemana, no se puede dejar de afirmar que Beling, en términos globales, es más actual que nunca. Si se intentan comparar las distintas concepciones de la teoría del delito de los diversos ordenamientos jurídicos se advierte con facilidad — asumiendo aquí el riesgo que toda simplificación implicaque el modelo postfinalista no es, en modo alguno, el dominante. ${ }^{5}$

Edmund Mezger habría de agregar a esta concepción causalista, su aportación axiológica en el factor de la voluntad humana, entendiendo a ésta

${ }^{4}$ AMBOS, Karl, "100 años de la 'Teoría del Delito' de Beling. ¿Renacimiento del concepto causal de delito en el ámbito internacional?", en Revista Electrónica de Ciencia penal y Criminología, ISSN 1695-1094, Madrid, 2007, p. 6, disponible en http://criminet.ugr.es/recpc/09/recpc09-05.pdf, consultado el 11 de febrero de 2015.

5 Ibídem, p. 9. 
como un aspecto donde se generan los niveles de gravedad del delito, y asimismo, los niveles de reprochabilidad al autor de delito.

Ahora, la corriente finalista tiene por contrapartida, en el pensamiento de Hans Wenzel, la concepción contraria al pensamiento causal, que como ya hemos visto, tiene su base en el valor o no valor de la acción típica en el resultado, en tanto que para el finalismo, en su Derecho Penal Alemán, niega ese elemento subjetivo de la voluntad, y en la construcción advierte la coincidencia de los trabajos de Armin Kauffman y Günter Stratenwerth, que se extiende hasta nuestros maestros Günther Jakobs y Claus Roxin.

Dice Wenzel, citado por nuestro amigo Carlos Daza Gómez, que ...la finalidad o el carácter final de la acción se basa en que el hombre puede prever, dentro de ciertos límites, las consecuencias de su actividad, proponerse por tanto, fines diversos y dirigir su actividad conforme a su plan. Actividad final es obrar orientando conscientemente a un fin, mientras que el acontecer causal no está dirigido a un fin, sino que es el resultante de los componentes causales en cada caso. Por eso la finalidad es evidente, la causalidad es ciega. ${ }^{6}$

Concluye el ínclito profesor universitario de la UNAM que

la conducta humana es ejercicio de acción final, es decir, posee una estructura lógico objetiva final: debe ser un concepto ontológico. La acción es conducta humana, conducida por la voluntad hacia un determinado fin. La finalidad perseguida, y por tanto, el contenido de la voluntad del sujeto, forman parte de la acción. La teoría finalista de la acción parte de esta idea: en los tipos de los delitos dolosos o en los culposos nos hallamos ante dos categorías autónomas, en las cuales, la acción presenta diversa estructura ontológica. ${ }^{7}$

6 DAZA GÓMEZ, Carlos, "Evolución doctrinal del finalismo", en Revista de la Facultad de Derecho en México, núm. 209-210, Septiembre-Diciembre de 1996, UNAM, México, 1996, p. 53.

7 Ibídem, p. 53. 


\section{La controversia de las corrientes doctrinales en la creación de la norma}

Ahora, para en Estado mexicano, la configuración de sus ordenamientos punitivos, han registrado un devaneo entre las dos teorías objeto de estudio de este texto, y en ese terreno, coincide el aspecto fáctico y abstracto de la acción del legislador y el jurista.

Ambos, en el planteamiento dogmático de la creación de la norma, coinciden en un momento y tiempo común que entremezcla ficción y realidad: la ficción es representada por las previsiones que desde sus intereses, sus posibilidades y sus capacidades de conocimiento de la realidad social, ambos actores creen en la pretensión de poder modificar a través de la norma su entorno, y la realidad, que es esa dimensión donde interactúan diversos factores que en conjunto representan esa percepción de lo que llamamos el mundo real, y que se rige por normas de distinta concepción, entre ellas, las normas jurídicas.

Se constata en esta ficción un amplio planteamiento de lo que es la punibilidad, es decir, que la perspectiva del ordenamiento jurídico penal es más bien prospectiva: el hecho futuro, el cómo podría ser el hecho, a diferencia de lo habitual, en retrospectiva, el hecho cometido.

Aquí, la política criminal en tanto interaccionismo entre norma y contexto social, (entre leyes, sistemas, instituciones, ciudadanos y operadores estatales), debe estar precedida necesariamente de una política de contenidos sociales (educación, religión, convenciones, costumbres), que se configure como una alternativa para proponer una norma penal sobre una base preventiva.

Hablamos, por supuesto, de una evolución de la idea meramente punitiva, para situarnos en una idea preventiva, de política criminológica integral, política donde participan sobre todo las estrategias estatales y sociales tendientes a minimizar los factores que prohíjan las condiciones para que se genere el delito en las actuales civilizaciones identificadas por la superación en función de los recursos materiales.

En este primer momento, jurista y legislador deben prevenir y considerar los variopintos sucesos y escenarios sociales para la formación de la norma, como lo es la familia, la religión, la política, la economía, entre 
otras, anticipándose su valoración a la creación de la norma, en un espacio físico y tiempo precisos, aspectos a los cuales hay que sumar el tipo de norma y la aplicación en un segmento poblacional ciertos; no se pueden crear normas jurídicas si no se contempla esta manera sistémica de ponderar los elementos súper-estructurales del Estado, porque en caso contrario, extraviaríamos los objetivos del jurista y el legislador dentro de la dogmática jurídica penal, y sin este planteamiento (previsión), no se puede configurar una norma penal adecuada a la necesidad del Estado y a las demandas de la sociedad, lo que redundarían en un carácter obsoleto de esa misma y de todas las propuestas legislativas derivadas de esa prima norma, además de riesgosas, en una sociedad afectada por diferentes expresiones del comportamiento antisocial.

Todo ello se debe considerar en el marco doctrinal que guíe el espíritu de la norma, pues la doctrina es la que dota de valores y legitimidad a la norma, de pertinencia y viabilidad, de certeza como parte integrante de una política criminológica en la cual se integran los esfuerzos del jurista y el legislador, binomio sin el que es imposible pensar en la racionalidad de la norma, ni la legalidad del ordenamiento jurídico.

Si bien la idea alemana sobre la dogmática jurídica infiere los significados instrumentales de la norma jurídica penal - como ocurre con otras corrientes jurídicas en el continente europeo-, encargándose de aspecto nodales de la teoría del delito — hablar de dogmática jurídica penal y de teoría del delito es hablar de una dimensión del conocimiento jurídico muy complementada e interdependiente, pues no puede haber teoría del delito sin dogmática jurídica penal_- para nosotros tiene mucho sentido reinterpretar esta idea dogmática jurídica, sobre la base del Programa de Marburgo, planteamiento que desde la estructura normativa de Liszt, implica una concepción dogmática de la norma, pero a su vez, como ya lo pudimos leer en subtítulos anteriores, amplía la posibilidad de pensar al derecho penal como un elemento que admite las contribuciones de las otras ciencias, a partir de la necesidad de observar al hecho criminal, al comportamiento antisocial como un hecho prevenible, a través de la funcional configuración de la norma.

Empero, cuando se trata de cómo construimos la norma desde la dogmática jurídica, desde la teoría del delito, entonces debemos analizar 
hacia dónde ha colocado su mirada el legislador mexicano, y a partir de esa mirada, qué hechos se han desenvuelto en el marco del sistema penal mexicano.

Para poder comprender primero la configuración doctrinal de nuestro sistema punitivo, es necesario hacer referencia a que en los inicios de 1994, en el Congreso de la Unión, se reformó el texto fundamental, a efecto de que, a través del código sustantivo, la figura del cuerpo del delito por los denominados elementos del tipo penal. El dolo se ubicó en estos elementos.

A partir de esa reforma, se generaron divergencias entre los agentes del Ministerio Público y los juzgadores, puesto que en la acción persecutora de los delitos, los jueces negaban las órdenes de aprehensión solicitadas por los agentes del Ministerio Público, a partir del argumento de la falta de pruebas para acreditar todos los elementos del tipo penal y la probable responsabilidad, y las mismas razones se utilizaban para dictar autos de libertad.

Lo anterior, nos dice Díaz Aranda,

generaba irritación en el seno del Ministerio Público y se llegó a iniciar averiguaciones previas en contra de los jueces que se negaban a librar dichas órdenes de aprehensión o dictaban autos de libertad en favor del consignado. Mientras los órganos de procuración e impartición de justicia sostenían la pugna antes descrita, la delincuencia se incrementó a niveles alarmantes. ${ }^{8}$

A efecto de disolver esta controversia fáctica, el legislador mexicano se aventuró a una nueva reforma constitucional en 1999, destacando para ello que se atendía una problemática que se describía en los siguientes términos:

La sociedad toda ha advertido en el pasado reciente serias deficiencias en el funcionamiento de nuestros sistemas de procuración y administración de justicia y lo que debía ser una colaboración de Ministerio Público y jueces en favor de la justicia,

8 DÍAZ-ARANDA, Enrique, Cuerpo del delito, probable responsabilidad y la reforma constitucional de 2008, Instituto de Investigaciones Jurídicas, UNAM, México, 2009, p. 10. 
ha derivado en una relación poco colaborativa entre estas dos instituciones públicas que recurrentemente se imputan mutuas fallas e ineficiencias, mientras que los delincuentes se benefician de esta situación.

Uno de los puntos de mayor conflicto entre estas dos instituciones ha sido precisamente el tema de los requisitos para obsequiar una orden de aprehensión, sobre todo a raíz de la reforma que sufrió el artículo 16 constitucional de 1993.

Siguiendo la doctrina finalista, la reforma de 1993 modificó el contenido de los artículos 16 y 19 de la Constitución, e impuso al Ministerio Público nuevos requisitos para obtener de la autoridad judicial el libramiento de órdenes de aprehensión y la expedición de autos de formal prisión, contra los probables responsables de delitos.

De esta manera, la reforma de 1993 propició que la legislación secundaria desarrollara los requisitos que debe demostrar el Ministerio Público para que la autoridad judicial pueda considerar integrados los elementos del tipo penal. Se establecieron formalidades y tecnicismos excesivos que obligan al Ministerio Público a integrar un expediente similar al requerido para dictar sentencia, con lo cual se convirtió la averiguación previa en un deficiente juicio previo a cargo del Ministerio Público.

Con el tiempo se han hecho evidentes las dificultades de aplicación práctica de las normas que regulan la orden de aprehensión y el auto de formal prisión, no sólo por las limitaciones de carácter técnico o profesional atribuidas a las autoridades encargadas de procurar justicia, sino también por razones de índole temporal, como en los casos de flagrancia o urgencia, en que el Ministerio Público tiene que integrar la averiguación previa y consignar a los probables responsables ante la autori- 
dad judicial en un plazo tan breve, que resulta imposible probar plenamente todos los elementos del tipo penal. ${ }^{\prime}$

El texto constitucional, recomendaba la iniciativa, debía abstenerse de caminar sobre las vías de una corriente doctrinal. Empero, en 1993, en la reforma sobre la temática en estudio, se adoptó una doctrina en materia penal que habría tenido éxito en otras naciones, pero cuya inadecuada concepción en nuestra normativa penal, no contribuyó de manera sustancial en la mejora de la procuración de justicia en nuestro país.

Como se puede advertir, el legislador de 1999 consideró que la doctrina final de acción, adoptada con la reforma de 1994, entorpeció la justicia penal en México; por ese motivo se pronunció contra dicha teoría y a favor de no adoptar teorías penales en el texto de la Constitución, específicamente en los artículos 16 y 19.

$\mathrm{Y}$ con esa bandera doctrinal hemos navegado hasta el momento, incluso con las diferentes promociones de leyes generales que se han adoptado a partir de la reforma constitucional procesal de 2008, y que acompañan al Código Penal federal en franca concurrencia que, por lo visto, ya no advierte al finalismo o al causalismo como doctrinas de las que se pueda prescindir, y por el contrario, la tipología penal advierte a manera de miscelánea conceptual la influencia de ambas fuentes de doctrina en la construcción de los tipos penales.

\section{Sistema penal de 2008: la mixtura doctrinal}

El nuevo sistema de justicia penal en su contexto procesal, como sabemos, pretende acabar con todas aquellas prácticas clientelares, que sólo obstruyen la impartición de justicia pronta y expedita consagrada en la Constitución, y asimismo, considera la oralidad como apuesta para derribar los hábitos de discrecionalidad indebida que ejercer de modo usual los operadores del sistema.

9 DÍAZ-ARANDA, Enrique, “Cuerpo del delito ¿causalismo o finalismo?”, en Díaz Aranda, Enrique (ed.), Problemas fundamentales de política criminal y derecho penal, Instituto de Investigaciones Jurídicas, UNAM, México, 2012, pp. 11 y 12. 
A ese esquema procesal renovado, la teoría del caso se ha colocado como una prioridad para la exposición, en las diferentes etapas del proceso penal, de los argumentos que deban destacar el agente del Ministerio Público y los abogados en su papel de contrapartes ante el poder judicial.

Con ello, planteamos el deslinde puntual de lo que es el aspecto procesal y el aspecto estrictamente sustantivo de la norma penal. De tal manera, el delito y su estudio, mantiene sus raíces en los sólidos terrenos de la doctrina jurídico penal, que para el caso que nos ocupa, se significan por el causalismo y el finalismo, principalmente, pues no olvidemos que también subsisten de modo alternativo, el funcionalismo, de Claus Roxin, que toma a la política criminal como base de su exposición, y del programa Alternativo alemán de la posguerra.

En nuestra legislación, el Código Penal Federal nos dice en su numeral 9 que "Obra dolosamente el que, conociendo los elementos del tipo penal, o previendo como posible el resultado típico, quiere o acepta la realización del hecho descrito por la ley", y que "Obra culposamente el que produce el resultado típico, que no previó siendo previsible o previó confiando en que no se produciría, en virtud de la violación a un deber de cuidado, que debía y podía observar según las circunstancias y condiciones personales".

Como podemos advertir en el dolo la teoría causalista se inocula en las consideraciones para integrar los elementos del tipo penal, en tanto que en la culpa, se advierten resabios de esa misma teoría, pero que al momento de pretender acreditarse cualquiera de los ilícitos con estos dos elementos, la determinación se vincula hacia el causalismo o finalismo dependiendo del ilícito de que se trate.

En la norma penal, los delitos que se encuentran establecidos en el Código Federal y en los Códigos de las entidades federativas, integran en sí ambas teorías en torno al dolo y la culpa.

Daremos para ese efecto dos ejemplos de cómo la esencia de ambas corrientes subsiste en el dolo y la culpa, a efecto de abrir el debate, en otro espacio, sobre esta mixtura doctrinal: 
a) En un delito de narcomenudeo, conforme a las disposiciones que se encuentran en la Ley General de Salud se enuncia en la Tabla de Orientación de Dosis Máximas de Consumo Personal e Inmediato, que, de acuerdo al artículo 479, podemos tener en nuestra posesión hasta 5 grs. de Cannabis Sativa, Indica o Mariguana para consumo personal, pero ¿qué pasa si nosotros tenemos en nuestro poder más de 5 gramos?

Incurriríamos en un delito de narcomenudeo y correspondería a los jueces o a los encargados de interpretar nuestra conducta para saber si desde una corriente causalista el hecho de tener más de la cantidad permitida nos hace acreedores de una punibilidad contemplada en la norma o si desde una teoría finalista deberá comprobarse el elemento subjetivo de que nuestra intención al tener más de la cantidad permitida era con algún fin de lucro con la venta de dicho narcótico y con ello hacernos acreedores a una punibilidad más amplia.

Esta es una interpretación que se vuelve personal por parte de los aplicadores del derecho ya que como lo explicamos anteriormente, no tenemos definida qué teoría es la que se debe tomar ya que nuestros códigos no fueron creados bajo una sólo de ellas sino que los encargados de crear la norma quizá ni si quiera tienen los conocimientos de la existencia de estas teorías y por lo tanto no crean tipos penales orientados sobre una misma corriente.

b) Otro ejemplo que podemos ocupar para ver el uso de las dos teorías es en los casos de secuestro en donde el artículo 11 de la Ley General para Prevenir y Sancionar los Delitos en Materia de Secuestro, nos dice:

"Artículo 11.- Si la víctima de los delitos previstos en la presente Ley es privada de la vida por los autores o partícipes de los mismos, se impondrá a estos una pena de ochenta a ciento cuarenta años de prisión y de doce mil a veinticuatro mil días multa".

Este artículo nos demuestra una interpretación causalista, ya que no importa si fueron autores o partícipes quienes privaron de la vida a la víctima, todos tendrán la misma responsabilidad dentro de la comisión del hecho. 
Pero no necesitamos ir muy lejos para explicar esto ya que si vamos al artículo 12 de la misma ley nos encontramos con lo siguiente:

"Artículo 12.- Si espontáneamente se libera a la víctima del secuestro dentro de los tres días siguientes al de la privación de la libertad, sin lograr alguno de los propósitos a que se refiere el artículo 9 de esta Ley y sin que se haya presentado alguna de las circunstancias agravantes del delito, la pena será de cuatro a doce años de prisión y de cien a trescientos días multa".

Ahora nos encontramos ante un dispositivo con carácter finalista ya que nos dice que si no se logra el propósito, o el fin como lo interpretamos nosotros, la punibilidad es menor que la del artículo anterior por lo que nos encontramos ante el problema de no tener leyes que sigan una sola corriente.

Estos dos ejemplos, se repiten en otros delitos contemplados en el esquema punitivo, y de ellos podemos advertir las diferencias sustantivas de cómo los juzgadores, por esta configuración de la norma nacida del imperio del legislador, tiende a identificar una heterogeneidad en las formas de leer, interpretar y aplicar las leyes penales, sea en el ámbito federal o local.

Y ello en estados como Tlaxcala, donde la función de procurar justicia se aviene a improvisaciones o manipulaciones, resulta un hecho controvertido en sí mismo.

\section{Reflexión final}

La teoría finalista afirma que el legislador al crear tipos penales debe estar sujeto a las estructuras permanentes de la teoría del delito y no violentar las estructuras para evitar caer en contradicciones. De tal modo que el legislador debe partir de los conceptos de acción, antijuricidad y culpabilidad, como estructuras fundamentales, que servirán para preservar los derechos fundamentales del hombre, es decir que su actividad creadora no debe ser autónoma, si no sujetarse a los principios de la teoría del delito.

Otro punto a considerarse es que para la teoría finalista de la acción, es que la culpabilidad debe ser con base en consideraciones política cri- 
minal, el apoyo legal de la pena y así mismo el límite de la pena con una garantía al individuo, ya que es una culpabilidad, que va más, con la personalidad del autor que a la consecuencia referida al hecho delictuoso, en este sentido la pena va a imponerse en consideraciones más bien de peligrosidad, que de estricta culpabilidad.

Es una garantía al individuo que la culpabilidad tenga en su consecuencia punitiva, límites precisos, pues de otra forma queda a merced del poder del Estado.

Los juristas que se agrupan en torno del sistema causalista, aceptan que el primer elemento del delito lo constituye una acción u omisión causal, que se concreta en un movimiento, o ausencia de movimiento, corporal voluntario; que el examen del proceso psicológico que determinó esa acción u omisión, es decir, del dolo o la culpa, no pertenecen al estudio de la fase objetiva del delito, sino a la subjetiva, o sea de la culpabilidad.

Para el causalismo, pertenece a la fase objetiva de la mecánica delictiva, la acción y la omisión, la tipicidad y la antijuricidad; a la fase subjetiva, corresponde la culpabilidad (el dolo la culpa), y para algunos la preterintencionalidad.

El sistema finalista, por el contrario, parte de una acción u omisión finalista; ubica el dolo y la culpa en el terreno de la acción y omisión típica; no acepta la distinción de los causalistas en fase objetiva y subjetiva del delito; le otorga a la culpabilidad un contenido diverso, excluyendo de este elemento el dolo y la culpa, que se ubican en el estudio de la tipicidad.

\section{Fuentes de información}

BAURMAN MICHAEL, Martí et al, Los desafíos de la democracia, $1^{\text {a }}$ ed., Editorial Fontamara, México, 2013.

AMBOS, Karl, “100 años de la 'Teoría del Delito’ de Beling. ¿Renacimiento del concepto causal de delito en el ámbito internacional?”, en Revista Electrónica de Ciencia penal y Criminología, ISSN 1695-1094, Madrid, 2007, p. 6, disponible en http:// criminet.ugr.es/recpc/09/ recpc09-05.pdf, consultado el 11 de febrero de 2017. 
BACIGALUPO, Enrique (2007), Lineamientos de la teoría del delito, Buenos Aires, Editorial Hammurabi, 2007.

DAZA GÓMEZ, Carlos, "Evolución doctrinal del finalismo", en Revista de la Facultad de Derecho en México, núm. 209-210, Septiembre-Diciembre de 1996, UNAM, México, 1996.

DÍAZ-ARANDA, Enrique, Cuerpo del delito, probable responsabilidad y la reforma constitucional de 2008, Instituto de Investigaciones Jurídicas, UNAM, México, 2009. "Cuerpo del delito ¿causalismo o finalismo?”, en Díaz Aranda, Enrique (ed.), Problemas fundamentales de politica criminal y derecho penal, Instituto de Investigaciones Jurídicas, UNAM, México, 2012.

JIMÉNEZ DE ASÚA, Luis, Teoría del Delito, Iure editores, edición española, Madrid, 2004.

Ley General de Salud, Reglamentaria del párrafo tercero del Artículo 4o. de la Constitución Política de los Estados Unidos Mexicanos.

Ley General Para Prevenir y Sancionar los Delitos en Materia de Secuestro, Reglamentaria de la Fracción XXI Del Artículo 73 de la Constitución Política de los Estados Unidos Mexicanos.

LISZT, Franz von, Tratado de derecho penal, vol. II (trad. Luis Jiménez de Asúa, Ed. Reus, Madrid, 2007, p. 262.

WENZEL, Hans, Derecho Penal Alemán, Editorial Jurídica de Chile. 